\title{
Student nurses' experience of supervision and Mentorship in clinical practice: A cross cultural perspective
}

\author{
M. Saarikoski ${ }^{a, *}, C_{\text {. Marrow }}{ }^{b}$, W. Abreu ${ }^{c}$, \\ O. Riklikiene ${ }^{d}$, S. Özbicakçi e
}

a Department of Health Care, Turku University of Applied Sciences, PL 20, 20701 Turku, Finland

b School of Nursing and Midwifery, St Martin's College, UK

c Escuela Superior de Enfermagem D. Ana Guedes, Porto, Portugal

d Kaunas University of Medicine, Lithuania

e Dokuz Eylûl University, School of Nursing, Turkey

Accepted 18 February 2007

\section{KEYWORDS \\ Nursing education; \\ Clinical practice; \\ Mentorship; \\ Thematic network}

\begin{abstract}
Summary This paper reports a study, which explored student nurses experience in clinical practice. The aims of this study were to describe nurse education systems in clinical practice in eight nursing schools and compare the supervisory experiences of student nurses working in clinical settings. The nursing schools taking part in the study were members of the thematic european nursing network (TENN). A quantitative survey method was chosen for the method of this study. The sample $(N=411)$ was collected using a validated research instrument from eight nursing schools participating in the TENN. The schools are located in Estonia, Belgium, Finland, Lithuania, Portugal, Romania, Turkey and United Kingdom. The data were collected during 2005. Although the nursing schools involved in TENN are in different development phases, however, the organisation of clinical practice is mainly similar. The percentage of clinical practice in a complete nursing programme varies from 38 to 57 . Moreover, the duration of the clinical placements varies substantially across the nursing schools; from a couple weeks to 34 weeks. Students in this study evaluated their supervision experience positively. In three schools group or team supervision is the most common model. In the clinical placements where the pedagogical activities of staff nurses are notable, is a clear tendency towards a Mentorship model. However, approximately $10 \%$ of respondents perceived some practical problems in the organisation of Mentorship. Students' total satisfaction was observed to link with crucial variables but only connection with the variable Occurrence of supervision was statistically significant $(p=0.000)$. (c) 2007 Elsevier Ltd. All rights reserved.
\end{abstract}

\footnotetext{
* Corresponding author. Tel.: +358 505985510; fax: +358 105535451.

E-mail address: mikko.saarikoski@turkuamk.fi (M. Saarikoski).
} 


\section{Introduction}

This paper reports a descriptive study, which explored experiences of student nurses in clinical practice in eight different nursing schools in Europe. There is also a common description of organisation of clinical practice in these schools. The schools were members in a European Union (EU) funded thematic european nursing network (TENN). The aim of this Network (2002-2005) was to define and develop a European dimension within a given academic discipline or other issues of common interest through cooperation between university faculties or departments, academic or professional associations and other partners. The nursing profession throughout Europe currently experiences differing education, standards and structures. For that reason, it is important to obtain a common picture of learning in nursing practice across the TENN member schools.

Professional and student mobility is low and it is difficult for many nurses to transfer their education and expertise in an appropriate manner across the EU. The TENN-network, which had 68 member institutions from 26 countries, started a number of important activities aimed at addressing these issues by building a recognised European base for the Nursing Profession and the network aims to continue to help promote excellence in nursing education and practice.

TENN commenced in 2002 and focused on three important areas of interest: nurse practitioner, Mentorship and clinical leadership incorporating clinical supervision (Marrow, 2006, 2004). As well as the other two key areas Mentorship was considered valuable in helping to achieve many aspects of the Bologna Process (European Commission, 2005). The aims of the subgroup Mentorship were to:

- To have reached a shared understanding of the concept of Mentorship and its application within the European nursing community and published the results of our endeavours;

- To have begun to develop a common framework for Mentorship that is transferable across countries and which facilitates the free movement of students and professionals alike.

\section{Background}

The concept of supervision is used here as an overarching concept, which refers to the guidance, support and assessment of student nurses by clinical staff. Supervision can take place with an individual supervisor, or in a group. The term Mentor is a subconcept and a formal supervisory role and is used to describe the role of a qualified nurse who facilitates learning and supervises students in the practice setting. The aim of the Mentor role is in supporting and helping student nurse to develop the necessary skills to become a competent and knowledgeable practitioner (ENB, 2001b; Bennett, 2003). Members of the Mentorship subgroup of TENN have collectively defined the term Mentor as a named personal supervisor who is working in clinical practice.

The term Link Teacher is used to describe the role of a teacher employed by educational institutions that have responsibility for ensuring that the Mentors and students in practice are supported and informed on current educational practices (Wills, 1997; ENB, 2001b). In this article, the term Link Teacher refers to the lecturer employed in the educational institution whose role covers both theoretical and clinical teaching. The professional background of the link teacher is mainly in nursing but like in this study, in one nursing school, the professional background of the link teacher was in medical science.

A number of research papers have described various aspects of student nurses' experiences in clinical practice. From the viewpoint of supervision, there are two main streams: clinical learning environment and supervisory relationship. The studies carried out during the 1980's highlighted strongly the meaning of learning environment and the role of the ward manager in this context (Ogier, 1981; Fretwell, 1983; Orton, 1983). The main point of these studies of 1980's was that the ward manager is a key person in the establishment of the ward as a good learning environment for student nurses.

In the 1990's, empirical studies illustrated the transition of interest from learning environment issues to the supervision practices of student nurses, especially, the individualised supervisory relationship (Marrow and Tatum, 1994; Marrow, 1995; Saarikoski, 2002). Moreover, the pedagogical activities of clinical nursing staff were seen as an important factor in the supervision of student nurses (Marrow, 1995). The one-to-one relationship between student and Mentor is crucial to the process of professional development (Myrick, 1988; Craddock, 1993; Earnshaw, 1995). The aim of the individualised supervision system is to enable a close relationship to develop between the Mentor and the student that will facilitate learning and provide individual support and guidance (Hsieh and Knowles, 1990; Dibert and Goldenberg, 1995; Sibson and Machen, 2003). 
Confidential supervision sessions are considered important because they enable those involved to talk about the student's own experiences and feelings (Laschinger and MacMaster, 1992; Shatkin, 1995; Crawford et al., 2000). Earlier the traditional model for supervision was group supervision (Holm et al., 1998; Heinonen, 2003), whereas current models emphasise one-to-one supervision (ENB, 2001a; Griswold-Peirce, 1991; Saarikoski, 2002). As practices of clinical teaching have changed, the role of the staff nurse has become more important in the clinical supervision process than before. However, it appears that the role of the staff nurse in the supervision of student nurses has only received a limited evaluation.

\section{The study}

\section{Context of the study}

As stated earlier, eight member schools of the TENN-network took part in this study. The schools are located in Belgium, Estonia, Finland, Lithuania,
Portugal, Romania, Turkey and in the UK. These schools represent a wide spectrum of the European Community. Although Turkey and Romania are not yet members of the EU they are widely considered European. Within these schools, the nurse education system differs, some more dramatically than others. The findings of this study cannot be generalised wider - e.g., to each country where schools are located. It is also important to recognise that differences between nursing schools can vary somewhat inside a country. For this reason, any generalisations cannot be done even on the level of the current country. In this paper, every school has got an alphabetical symbol $(B, E, F$, etc.) because the (real) names of the schools are not needed.

The educational organisations of general nurse education varied from vocational college to independent university department. Examinations varied from a three-year full time Diploma to four-years Bachelor of Art (BA) degree - all schools give registered general nurse examinations which are valid in these countries. Basic information presented in the Table 1 has been given by a nurse teacher delegate of the every nursing school.

Table 1 Basic features in organisation of general nurse education and clinical practice in eight nursing schools of TENN

\begin{tabular}{|c|c|c|c|c|c|c|c|}
\hline \multirow[t]{2}{*}{ A school: } & \multicolumn{3}{|c|}{ Education system: } & \multicolumn{4}{|c|}{ Organisation of clinical practice: } \\
\hline & $\begin{array}{l}\text { Responsible } \\
\text { operative } \\
\text { organisation }\end{array}$ & $\begin{array}{l}\text { Duration of } \\
\text { the total } \\
\text { programme }\end{array}$ & $\begin{array}{l}\text { Academic } \\
\text { level of } \\
\text { education }\end{array}$ & $\begin{array}{l}\text { Responsible } \\
\text { organisation }\end{array}$ & $\begin{array}{l}\text { Percentage } \\
\text { ratio of total } \\
\text { course }\end{array}$ & $\begin{array}{l}\text { Working } \\
\text { during } \\
\text { weekends? }\end{array}$ & $\begin{array}{l}\text { Role of } \\
\text { a link } \\
\text { teacher }\end{array}$ \\
\hline School $B$ & Polytechnic & 3 Years & Diploma & School & $50 \%$ & Seldom & $\begin{array}{l}\text { Liaison, } \\
\text { evaluation, } \\
\text { teaching }\end{array}$ \\
\hline School $E$ & College & $31 \frac{1}{2}$ Years & Diploma & School & $40 \%$ & No & $\begin{array}{l}\text { Liaison, } \\
\text { evaluation }\end{array}$ \\
\hline School $F$ & Polytechnic & $31 / 2$ Years & Degree & School & $38 \%$ & Seldom & $\begin{array}{l}\text { Liaison, } \\
\text { evaluation }\end{array}$ \\
\hline School $L$ & $\begin{array}{l}\text { University or } \\
\text { college }\end{array}$ & $\begin{array}{l}4 \text { or } \\
31 / 2 \text { Years }\end{array}$ & $\begin{array}{l}\text { Degree }(4 \mathrm{y}) \text {, } \\
\text { diploma } \\
\left(3 \frac{1}{2} \mathrm{y}\right)\end{array}$ & School & $50 \%$ & No & $\begin{array}{l}\text { Liaison, } \\
\text { evaluation }\end{array}$ \\
\hline School $P$ & $\begin{array}{l}\text { University or } \\
\text { Polytechnic }\end{array}$ & 4 Years & Diploma & School & $57 \%$ & $\begin{array}{l}\text { Yes, during } \\
\text { last } 6 \\
\text { months }^{a}\end{array}$ & $\begin{array}{l}\text { Liaison, } \\
\text { evaluation, } \\
\text { teaching }\end{array}$ \\
\hline School $R$ & $\begin{array}{l}\text { University } \\
\text { college }\end{array}$ & 3 Years & Diploma & School & $50 \%$ & Yes & $\begin{array}{l}\text { Liaison, } \\
\text { evaluation, } \\
\text { teaching }^{\text {b }}\end{array}$ \\
\hline School $T$ & $\begin{array}{l}\text { University } \\
\text { department }\end{array}$ & 4 Years & Degree & School & $53 \%$ & Yes & $\begin{array}{l}\text { Liaison, } \\
\text { evaluation, } \\
\text { teaching }\end{array}$ \\
\hline School U & $\begin{array}{l}\text { University } \\
\text { college }\end{array}$ & 3 Years & $\begin{array}{l}\text { Diploma or } \\
\text { honours } \\
\text { degree }\end{array}$ & School & $50 \%$ & Yes & $\begin{array}{l}\text { Liaison, } \\
\text { evaluation }\end{array}$ \\
\hline
\end{tabular}

\footnotetext{
${ }^{a}$ Not compulsory.

b Physician (medical staff).
} 
There are some differences in the organisation of clinical practice in these eight schools. The percentage of clinical practice in the total programmes varied from $38 \%$ to $57 \%$. It differed strongly by the studying years in some schools; e.g., in school $T$, the proportion of clinical practice is $89 \%$ during the last studying year. The role of link teacher is not the focus of this study, however, some issues from the perspective of clinical practice were explored. The role of the teacher focuses on liaison and evaluation in four schools and in the other four schools ( $B, P, R$ and $T$ ) teaching of practical skills is also an integral part of the teachers' role. There are also many similarities. In every school of the sample, the responsibility of organising clinical practice rests with the education personnel, not the hospital. The role of student nurses is also quite clear in all the schools; students are learners and are therefore supernumerary and not part of the rostered numbers. Only in three schools did students work on a regular basis including weekends.

\section{Aims}

The aim of this study was to describe nurse education system in clinical practice in eight European nursing schools and explore the supervisory experiences of student nurses working in clinical settings. The specific objectives were to explore:

1. How studying and teaching in clinical practice is organised in eight TENN member schools?

2. How supervision of student nurses in clinical practice was organised in these schools?

3. How nursing students experience supervision in the clinical placements?

\section{Methods and research design}

A quantitative survey method was chosen for the method of this study. A part of a validated research instrument, CLES scale (Saarikoski and Leino-Kilpi, 2002) was used. The reliability of a sub-scale was estimated using Cronbach's alpha coefficient. In this sample, its value was 0.93 . In the validation process, of the CLES, the internal consistency reliability of this sub-scale was 0.94 (Saarikoski, 2002). Additionally the delegates of the schools gave information connecting the education system of general nurse in their schools (see Table 1).

The purposive sample $(N=411)$ was collected from eight nursing schools of the TENN-network. Four schools $(B, F, P$ and $U)$ chosen for the sample are located in the countries which have been members of the EU for 10 years or longer and in line with the EU's Directive 92/51 (1992) which ensures a similar mainline of education. Two of the schools $-E$ and $L-$ are located in the countries that are new members (since 2004) under the supervision of the educational norms of the EU. Schools $R$ and $T$ are located in countries, which are not yet members of EU. This combination of schools is reasonable for the combination of TENN member schools for obtaining a common picture across the TENN member schools. The data was collected from one or two student groups per school.

\section{The questionnaire and data collection}

The questionnaire used in this study was developed from an extensive literature review of clinical learning environments and supervision from 1980's and 1990's. The clinical learning environment and supervision scale (CLES) (Saarikoski and Leino-Kilpi, 2002) consists of background variables focusing on the student, their hospital and ward type, workload and patient dependency levels of the ward, duration of placement, meeting frequency of clinical teacher and students' total satisfaction with the clinical period. In the CLES scale, there are 27 statements involving the learning environment and supervision relationship but in this study only the items (11) of Supervisory relationship were used.

This part of the scale includes questions concerning: (a) occupational title of supervisor, (b) how supervision occurred on the ward and (c) eight statements illustrating the content of supervisory relationship. To these statements of the CLES' sub-scale the students responded using a five-steps rating scale. The alternatives of the scale were: (1) fully disagree; (2) disagree to some extent; (3) neither agree nor disagree; (4) agree to some extent and (5) fully agree.

All the eight schools participating in this study are located in the eight different countries and have their own languages. CLES scale has been published in English (Saarikoski and Leino-Kilpi, 2002) but for more trustful results of this study, the questionnaire was translated to local languages. A contact person of every school translated the background variables from English to his or her own language. The proper parts of the CLES scale (connecting to supervision) were translated using a specific three steps procedure to provide semantic equivalence (White and Elander, 1992; Behling and Law, 2000). Firstly, a country delegate of this study translated the Supervisory items to his or 
her own language (language X). Secondly, an X-language speaking English lecturer translated this new instrument version (X-language) back to English as a 'blind'. Finally, in the consensual phase, a native English speaking nurse teacher reviewed the original items, and the double-translated items. He gave a rapport (to the school delegate) about the items as the basic idea of the item had changed during this translation process. After that, the current school delegate made the needed adjustments. There was also in the questionnaire definitions of the concepts of supervision and Mentorship.

The sample consisted of first, second and third year students. All respondents were, at the time of the study, undertaking a clinical placement in a range of different clinical specialities. Students were asked to evaluate their just completed clinical placement using the questions and statements of the CLES scale. The data were collected in spring of 2005.

\section{Ethical considerations}

All ethical standards of research were observed: anonymity, voluntarity and rights to refuse to participate were guaranteed to respondents (Burns and Grove, 1997). Written permission to carry out the study was obtained from directors of the nursing colleges, polytechnics and the university departments.

During the data collection phase, the respondents' right to privacy was protected. The design of the study did not demand the use of identifiable questionnaires: data was collected at the end of a clinical placement using an anonymous questionnaire. All respondents volunteered to take part in the study and they gave their consent verbally.

\section{Results}

\section{Participants}

The mean age of the respondents was 24 years (SD 0.92 ), $91 \%$ of them were female. There were two sub-samples (Schools $L$ and $T$ ) without any male students (Table 2 ).

The clinical placements had occurred in eight different ward types. Most common ward types were medical wards $(25 \%)$, paediatric wards $(23 \%)$ and surgical wards (22\%). The reminder (30\%) were, (in the order of frequency) psychiatric wards, geriatric wards, nursing homes, gynaecology wards and oncology wards. Duration of the placements varied strongly by the schools (Table 3 ).

The mean value of the duration of the clinical placements was seven weeks in the whole sample; clinical placements were shortest in school $L$ (mean three weeks) and longest in school $R$ (mean 23 weeks). The majority of the students $(66 \%)$ were located in the classified scale to the segment of approximately 1-2 months.

\section{How supervision was organised?}

The most common occupational background of a supervisor was a staff nurse (63\%). The differences between the schools were small - excluding school $R$ where physicians act as supervisors for the student nurses. In the clinical placements of school $T$, staff nurses do not act officially as supervising Mentors but Ward Manager and nurse teachers are the persons responsible for the teaching and supervision of student nurses in clinical practice. The role of the Ward Manager or assistant Ward Manager is important also in the supervision system of schools $L(62 \%), E(41 \%)$ and $U(30 \%)$ (Table 4$)$.

Table 2 Respondents of the study by the schools $(N=411)$

\begin{tabular}{lllllll}
\hline A school: & \multicolumn{2}{l}{ Number of respondents } & Age mean & SD & \multicolumn{2}{c}{ Male students } \\
\cline { 2 - 4 } \cline { 6 - 7 } & $n$ & Percentage (\%) & & & $n$ & Percentage of the sub-sample (\%) \\
\hline School $B$ & 38 & 9.2 & 24 & 0.83 & 6 & 16 \\
School $E$ & 46 & 11.2 & 23 & 1.05 & 3 & 7 \\
School $F$ & 67 & 16.3 & 24 & 0.95 & 4 & 6 \\
School $L$ & 26 & 6.3 & 22 & 1.12 & 0 & \\
School $P$ & 76 & 18.6 & 23 & 0.77 & 12 & 16 \\
School $R$ & 65 & 15.8 & 24 & 0.67 & 4 & 6 \\
School $T$ & 46 & 11.2 & 24 & 0.99 & 0 & \\
School $U$ & 47 & 11.4 & 28 & 0.82 & 7 & 15 \\
& 411 & $100 \%$ & 24 & 0.92 & 36 & $9 \%$ \\
\hline
\end{tabular}


Table 3 Duration of placements by the schools (percentages and frequencies)

\begin{tabular}{llllll}
\hline Country & Mean (limits) & $2-3$ Weeks & App. 1-2 months & App. 3 mon. & Over 3 months \\
\hline School $B$ & 4 Weeks (2-6) & $29 \%(11)$ & $71 \%(27)$ & 0 & 0 \\
School $E$ & 5 Weeks (4-18) & 0 & $96 \%(44)$ & 0 & $4 \%(2)$ \\
School $F$ & 5 Weeks (2-8) & $19 \%(13)$ & $81 \%(54)$ & 0 & 0 \\
School $L$ & 3 Weeks (2-4) & $89 \%(23)$ & $11 \%(3)$ & 0 & 0 \\
School $P$ & 5 Weeks (4-5) & 0 & $100 \%(76)$ & 0 & 0 \\
School $R$ & 23 Weeks (15-34) & 0 & 0 & 0 & $100 \%(65)$ \\
School $T$ & 4 Weeks (3-5) & $4 \%(2)$ & $96 \%(44)$ & 0 & 0 \\
School $U$ & 9 Weeks (4-15) & 0 & $45 \%(21)$ & $47 \%(22)$ & $8 \%(4)$ \\
Total & 7 Weeks $(2-34)$ & $12 \%(49)$ & $66 \%(269)$ & $5 \%(22)$ & $17 \%(71)$ \\
\hline
\end{tabular}

Table 4 Occupational title of supervisor by the schools (percentages and frequencies) $(N=411)$

\begin{tabular}{llllll}
\hline Country & Staff nurse & Nurse specialist & Ward manager (WM) & Assistant WM & Medical staff \\
\hline School $B$ & $97 \%(37)$ & $3 \%(1)$ & 0 & 0 & 0 \\
School $E$ & $39 \%(18)$ & $20 \%(9)$ & $6 \%(3)$ & $35 \%(16)$ & 0 \\
School $F$ & $72 \%(48)$ & $27 \%(18)$ & 0 & $1 \%(1)$ & 0 \\
School $L$ & $38 \%(10)$ & 0 & $54 \%(14)$ & $8 \%(2)$ & 0 \\
School $P$ & $100 \%(76)$ & 0 & 0 & 0 & 0 \\
School $R$ & 0 & 0 & 0 & 0 & $100 \%(65)$ \\
School $T$ & 0 & 0 & $100 \%(46)$ & 0 & 0 \\
School $U$ & $70 \%(33)$ & 0 & $19 \%(9)$ & $11 \%(5)$ & 0 \\
Total & $63 \%(260)$ & $7 \%(27)$ & $8 \%(31)$ & $6 \%(24)$ & $16 \%(68)$ \\
\hline
\end{tabular}

\section{Occurrence of supervision}

The questionnaire included six different options for the occurrence of supervision on the ward:

1. The student did not have a named supervisor;

2. A personal supervisor was named, but the relationship with this person did not work;

3. The named supervisor changed during the training course, even though no change had been planned;

4. The supervisor varied according to shift or place of work;

5. The same supervisor had several students (socalled group supervision);

6. The named supervisor was Mentor and the relationship worked in practice.

For statistical analyses, the three first alternatives were combined into one class: Unsuccessful supervisory experience and alternatives 4 and 5 were combined as: Group or team supervision.

The most common perception among respondents was option 6; 215 students (53\%) assessed that they had had a successful Mentorship, 157 students (38\%) had had group or team supervision and 37 (9\%) had some variation of unsuccessful supervisory experience (missing two cases).

\section{How nursing students experience supervision in the clinical placements?}

Students evaluated the quality of the Supervisory relationship using CLES's (Saarikoski and Leino-Kilpi, 2002). Supervisory sub-dimension which consisted of eight statements that measured the pedagogical and psychological content of the relationship. The statements relate to the: (1) attitude of the Mentor, (2) individuality of supervision, (3) continual feedback, (4) satisfaction of the student, (5) equality of relationship, (6) mutuality of interaction, (7) respect of relationship and (8) sense of trust. All statements were called positive statements and students evaluated them using a fivesteps rating scale. For statistical analyses, two first steps (fully disagree and disagree to some extent) were combined and named for Negative assessment. The medium of the scale was named Neutral assessment and steps 4 and 5 (agree to some extent and fully agree) were combined and named Positive assessment.

The students evaluated their supervisory relationship as 'good'. The biggest part of respondents (35\%) assessed their supervisory relationship with positive assessment and only $16 \%$ with negative assessment. The mean of the sum-variable was 
3.90 (on $1-5$ scale) in the whole sample. Highest mean values were in the schools where students have lot of successful Mentorship experiences (e.g., school $P$ and school $U$ ).

The questionnaire included one question and one statement, which explored the students' satisfaction: How satisfied are you with the placement that has just ended? and Overall I am satisfied with the supervision I received (one statement of the sum-variable Content of supervisory relationship). These items were combined for a sum-variable Total satisfaction. The values of this variable varied between 3.1 and 3.9 by the schools and the mean was 3.6. Differences between schools were not statistically significant ( $p$-value in ANOVA 0.07).

Total satisfaction was observed to link with some crucial variables; by sub-samples, gender and age of respondent, physical and mental stress load of the placement, patient dependency levels, and contact frequency with a link teacher and the occurrence of supervision. Only the last one variable had statistical significant connection with the total satisfaction of students (Table 5 ).

\section{Discussions}

\section{Limitations of the study}

Typifying of the sample causes the biggest limitation of this study. Single sub-samples are small and are not representative of the current country. Every sub-sample consists only of one or two student groups in one nursing college, polytechnic or unit of university. There are, in this sample few schools where the education system is not yet ready for Mentorship, that said they are developing. The results show the situation only in these single schools, not on national level.

The second limitation of the study is the significant differences between these schools; they do, however, represent a wide spectrum of European culture and development phases of nursing education. For these reasons, many practices of clinical learning are different. When practices are different, the terms and concepts are also different. Even in the planning phase of this study, the contents and meanings of concepts were highlighted and there was still a small risk for mistakes and misunderstandings. We tried to overcome this limitation with a careful double translation of the research instrument.

Even though there are limitations to this study the findings are important. If we are to move the knowledge base on supervision and Mentorship forward and facilitate Schools of Nursing to examine and develop their supervisory systems, we need to understand the practice from the students' perspective.

\section{Consideration of results}

The main factors in the organisation of clinical practice are similar in all eight nursing schools involved in this study. In all the schools, the responsibility of organising clinical practice rests with the educational organisation, not the hospital. Student nurses are learners, and thus, not part of the rostered numbers - even the developmental phase of the education system differs between schools. (Table 1). Membership of the EU indicates compliance with the EU Directive (1992) which ensures similar key principles of education in six nursing schools of this study. The duration of education of a registered general nurse varies between three and four years and the academic level can be either diploma or degree. The majority of students (66\%) spend 1-2 month's in one clinical experience (mean of the sample is seven weeks). The students of school $R$ present a clear exception; every student spends over three months in one clinical placement. This can be considered from two perspectives: that there is a different pedagogical phi-

Table 5 Cross tabulation of occurrence of supervision and students' total satisfaction (percentages and frequencies) ( $N=409$, missing 2$)$

\begin{tabular}{lllll}
\hline Occurrence of supervision: & \multicolumn{3}{l}{ Total satisfaction: } \\
\cline { 2 - 5 } & $\begin{array}{l}\text { Unsatisfied } \\
\text { students }\end{array}$ & $\begin{array}{l}\text { Neither unsatisfied, } \\
\text { nor satisfied }\end{array}$ & Satisfied students & Total \\
\hline Unsuccessful experience of supervision & $46 \%(17)$ & $43 \%(16)$ & $11 \%(4)$ & $100 \%(37)$ \\
Group or team supervision & $12 \%(19)$ & $61 \%(95)$ & $27 \%(43)$ & $100 \%(157)$ \\
Successful Mentorship & $6 \%(12)$ & $41 \%(88)$ & $53 \%(115)$ & $100 \%(215)$ \\
Total & $12 \%(48)$ & $49 \%(199)$ & $39 \%(162)$ & $100 \%(409)$ \\
\hline
\end{tabular}

$p$-Value in Pearson Chi-Square test $0.000^{\text {"w**. }}$.

In one cell (11.1\%) have expected count less than 5 , the minimum expected count is 4.34 . 
losophy or it relates to a system where learners are more like apprentices than students. However, in relation to the duration of the placements there is no clear profile, which complies with the development phase of the education system (e.g., ratification of EU directive 92/51/EEC).

Clinical nurses act mainly as supervisors and Mentors for student nurses. In the schools where other members of staff other than staff nurses acted as supervisors, the models of group or team supervision were more common. In the clinical placements where staff nurses act as supervisors, there is a clear tendency toward a Mentorship model. There are, however, some practical problems in the organisation of the Mentorship based supervision model; a Mentor can change or the relationship may not work at all. Organising Mentorship in a health care unit where staff nurses work weekend and night shifts is also a challenging process, especially in the shorter placements.

Students in every sub-sample of this study evaluated their supervision experience positively. Students' total satisfaction was observed to link with all variables but only the variable Occurrence of supervision was statistically significant ( $p$-value in Chi test 0.000). This is remarkable result as it signifies that Mentorship relationship and a satisfied student go hand in hand. The continued movement towards the one-to-one supervisory relationships is seen as being important to the advancement of supervision systems. The most satisfied students were those who had a formal Mentorship relationship. The most frequently cited cause of a poor experience was a supervisory relationship with some practical problems; e.g., a personal supervisor (Mentor) was named, but the relationship with this Mentor did not work or the Mentor changed during the placement, even though no change had been planned. These results support those of earlier studies undertaken in the 90's (Hsieh and Knowles, 1990; Laschinger and MacMaster, 1992; Dibert and Goldenberg, 1995; Shatkin, 1995).

However, some problems still inhibit this process but these problems have been postulated and include Mentor-training programmes for staff nurses. This kind of solution is based on the presumption that the supervision of student nurses is a separate activity from clinical practice, and which does not have significant connections to other parts of the ward culture. Training programmes for Mentors is crucial but not sufficient in the development of more effective supervisory systems. There should be clear strategies in place which identify the responsibilities and skills required on both the supervisor and student part.

\section{Conclusions}

In Europe, it is the ongoing collaborative work such as TENN, which contributes to the development of nurse education, nursing practice and improvements in the working environment. The European Commission's Advisory Committee on Training in Nursing (ACTN, 2003) has started to define minimum standards for the content and duration of basic nurse education in all countries included in the EU. A new challenge is the latest enlargement when many new countries from Eastern Europe have joined the EU. In these countries, an independent nursing culture is in the developing phase (An Board Altranais, 2004). Hence, there is a need to integrate the clinical training of pre-registration education in the EU. The educational system must be comprehensive and designed to balance academic and clinical competencies. Such integration has been given strategic importance through national directives, national curricula, which order the organisation of clinical education at a national level. This integration process needs more research, which is focused on these emerging nursing educational systems and must be internationally organised with much larger sub-samples than in this study.

\section{References}

ACTN/Advisory Committee on Training in Nursing, 2003. Position papers (online). Available from: <http://www.pcn.yucom. be/Position_papers/education_executive_summary.html> (referred 17.04.2003).

An Board Altranais, 2004. Supporting the development of nursing and midwifery within a new enlarges European Union: An explorative review (online). Available from the World Wide Web: <http://nursingboard.ie/Education> (referred 10.11 . 2005).

Behling, O., Law, K.S., 2000. Translating Questionnaires and Other Research Instruments: Problems and Solutions. Saga Publications Inc., Thousand Oaks.

Bennett, C.L., 2003. How to be a good Mentor. Nursing Standard 17 (36), 1-14.

Burns, N., Grove, S.K., 1997. The Practice of Nursing Research, third ed. W B Saunders Company, Philadelphia, London.

Craddock, E., 1993. Developing the facilitator role in the clinical area. Nurse Education Today 13, 217-224.

Crawford, M.J., Dresen, S.E., Tschikota, S.E., 2000. From 'getting to know you' to 'soloing': The preceptor-student relationship. Nursing Times Research 5, 5-19.

Dibert, C., Goldenberg, D., 1995. Preceptors' perceptions of benefits, rewards, supports and commitment to the preceptor role. Journal of Advanced Nursing 21, 11441151.

ENB/English National Board, 2001a. Placements in focus. Guidance for education on practice for health care professions. ENB, Department of Health. 
ENB/English National Board, 2001b. Preparation of Mentors and teachers. A new framework of guidance. ENB, Department of Health.

Earnshaw, G.J., 1995. Mentorship: The student's view. Nurse Education Today 15, 274-279.

European Commission, 2005. Education and Training [online] Available from:<http://europa.eu.int/comm/education/ policies/2010/et_2010_en.html> (referred 22.11.2005).

European Union, 1992. Directive 92/51/EEC.

Fretwell, J.E., 1983. Creating a ward learning environment: The sister's role. Nursing Times 79, Occasional papers (21), 3739 and (22), 42-44.

Griswold-Peirce, A., 1991. Preceptorial students' view of their clinical experience. Journal of Nursing Education 30, 244-250.

Heinonen, N., 2003. Terveysalan koulutuksen työssäoppiminen ja ohjattu harjoittelu. Sosiaali- ja terveysministeriön monisteita 2003: 22. OPM, Helsinki.

Holm, A-K., Lantz, I., Severinsson, E., 1998. Nursing students' experiences of the effects of continual process-orientated groups supervision. Journal of Nursing Management 6, 105113.

Hsieh, N.L., Knowles, D.W., 1990. Instructor facilitation of the preceptorship relationship in nursing education. Journal of Nursing Education 29, 262-268.

Laschinger, H.K.S., MacMaster, E., 1992. Effect of pregraduate preceptorship experience on development of adaptive competencies of baccalaureate nursing students. Journal of Nursing Education 31, 258-264.

Marrow, C.E., 2006. Guest Editorial. Developing nurse education and practice across the European Union. Journal of Research in Nursing 11, 289-291.

Marrow, C.E., 2004. Promoting excellence in nursing practice and education across Europe. Clinical, Nursing and Patient
Care: Education and Training. C2-C3. Hospital Healthcare Europe 2004/2005.

Marrow, C.E., 1995. Clinical supervision in action: Problems and dilemmas. Unpublished M. Phil Thesis, Lancaster University, Lancaster.

Marrow, C.E., Tatum, S., 1994. Student supervision: Myth or reality? Journal of Advanced Nursing 19, 1247-1255.

Myrick, F., 1988. Preceptorship: A viable alternative clinical teaching strategy? Journal of Advanced Nursing 13, 588591.

Ogier, M.E., 1981. Ward sisters and their influence upon nurse learners. Nursing Times 77, Occasional papers (11), 41-43.

Orton, H.D., 1983. Ward learning climate and student nurse response. In: Davis, B.D. (Ed.), Research into Nurse Education. Croom Helm, London, pp. 90-105.

Saarikoski, M., 2002. Clinical learning environment and supervision. Development and validation of the CLES evaluation scale. Doctoral dissertation, University of Turku, Annales Universitatis Turkuensis, Ser. D 525.

Saarikoski, M., Leino-Kilpi, H., 2002. The clinical learning and supervision by staff nurses: Developing the instrument. International Journal of Nursing Studies 39, 259-267.

Shatkin, L., 1995. Clinical teaching as part of psychiatric nursing education. The International Journal of Psychiatric Nursing Research 2, 134-145.

Sibson, L., Machen, I., 2003. Practice nurses as Mentors for student nurses: As untapped educational resource? Nurse Education in Practice 3, 144-154.

White, M., Elander, G., 1992. Translation of an instrument. Scandinavian Journal of Caring Sciences 6, 161-164.

Wills, M.E., 1997. Link teacher behaviours: Student nurses' perceptions. Nurse Education Today 17, 232-246.

Available online at www.sciencedirect.com

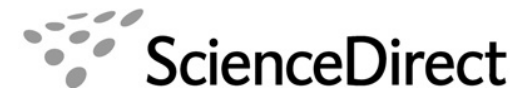

